\title{
Residential Demand for Electricity and Natural Gas in Pakistan
}

\author{
MAHMOOD IQBAL*
}

A model for residential demand for fuel in Pakistan was developed on the basis of stock of fuel-consuming appliances and their rate of utilization. Income and price elasticities of natural gas and electricity are estimated by the OLS and GLS methods. The income elasticity of natural gas and electricity and price elasticity of natural gas are found statistically significant and consistent with $a$ priori knowledge of economic theory. Several policy implications are pointed out and suggestions are made for improvement in future estimations.

The energy sector in Pakistan has received close attention in the various national development plans. The share of the fuel and power sector rose from about 12 percent to 18 percent of the development outlay during the $1955-80$ period [10]. However, few studies have focused on the sectoral consumption of various forms of energy in Pakistan. The aim of this study is to analyze the consumption pattern of commercial energy, namely, natural gas and electricity, in the residential sector of Pakistan. These two sources of energy provide 58 percent of the total supply of commercial energy; 19 percent of this supply was consumed by the residential sector alone [13].

Using the standard theory of demand, this study will analyze the importance of fuel expenditure in the consumer's budget and its sensitivity to changes in income and prices. It should help policy makers in examining the effectiveness of measures of demand management and price regulation used from time to time.

This paper is divided into three sections. In Section I, we develop a model of consumer demand for fuel. The basic hypothesis is that the demand for fuel depends on the stock of appliances and the intensity with which they are used. In Section II, the OLS technique is used to estimate the demand equations. Equations with autocorrelated residuals are estimated by the GLS method to obtain the non-serially correlated residuals. The results of the regression equations and income and price elasticities of demand for fuel are also explained in this section. Finally, in Section III, we point out some policy implications. We also make some suggestions, based on our model, for further study of residential demand for fuel in Pakistan.

* The author is a Ph.D. candidate in Economics at Simon Fraser University, Canada. This study was initiated when the author was a Visiting Economist at the Applied Economics Research Centre, University of Karachi, Pakistan. He is deeply indebted to Professor Mahmood H. Khan for giving valuable suggestions and improving the style of the paper. He is grateful to Dr. T. M. Heaps for his detailed comments. The author alone is responsible for any errors or omissions. 


\section{MODEL}

The model of residential demand for fuel is based on the postulates of the traditional micro-economic theory. A consumer's objective is to maximize utility, subject to a budget constraint. In this study, an additional constraint is imposed: the amount of fuel consumed is less than or equal to the 'capacity' - measured in TOE - of the consumer's stock of appliances. ${ }^{1}$ This stock is in turn dependent on the price of fuel, prices of appliances and the real income of the consumer.

Therefore, if ' $F$ ' stands for the demand for fuel, ' $\delta$ ' for the rate of utilization of appliances - assumed to be constant and same for all appliances - and ' $K$ ' for the stock of appliances, the demand equation can be expressed as $[1 ; 9 ; 18]$ :

$$
F=\delta K
$$

In the log-linear form, Eq. (1) can be written as: ${ }^{2}$

$$
\ln F=\ln \delta+\ln K
$$

Further, we assume that ' $\delta$ ' is a log-linear function of $m$-variables, the ' $X_{i}^{\prime}$ ' (income, relative prices of different kinds of fuel, temperature, etc.) as:

$$
\ln \delta=\sum_{i=1}^{m} \alpha_{i} \ln X_{i}+u
$$

where $u$ is the random error in the log form. Substituting Eq. (3) into Eq. (2):

$$
\begin{aligned}
& \ln F=\sum_{i=1}^{m} \alpha_{i} \ln X_{i}+u+\ln K \\
& \ln K=\ln F-\Sigma \alpha_{i} \ln X_{i}-u
\end{aligned}
$$

To eliminate the need for data on ' $K$ ', we assume that consumer is in the process of continuous partial adjustment towards a desired level of appliance holdings, $K^{*} . K^{*}$ is assumed to depend on $l$-variables, ' $Y_{j}$ ', all of which may have appeared in ' $X_{i}$ '. In the $\log$-linear form, it can be written as:

$$
\ln K^{*}=\sum_{j=1}^{l} \beta_{j} \ln Y_{j}+\epsilon
$$

where $\epsilon$ is a random error in $\log$ form. We also assume that the partial adjustment process takes the form:

$$
\ln K_{t}-\ln K_{t-1}=\phi\left(\ln K_{t}^{*}-\ln K_{t-1}\right) \quad 0<\phi \leqslant 1
$$

${ }^{1}$ The capacity of appliances are usually measured in KWH. Here we have converted one $\mathrm{KWH}$ into one Tone of Equivalent (TOE) by dividing the former with a factor of 4200 [14].

${ }^{2}$ Small Roman letters stand for logarithms of economic variables. The logarithm specification yields better results in terms of the significance of the estimated parameters. It has the added advantage that the coefficients are interpreted as demand elasticities [8].
Substituting Eq. (5) into Eq. (7):

$$
\begin{aligned}
& \ln F_{t}-\sum_{i=1}^{m} \alpha_{i} \ln X_{i t}-u_{t}-\ln F_{t-1}+\sum_{i=1}^{m} \alpha_{i} \ln X_{i t-1}+u_{t-1} \\
& =\phi \ln K_{t}^{*}-\phi \ln F_{t-1}+\phi \sum_{i=1}^{m} \alpha_{i} \ln X_{i t-1}+\phi u_{t-1}
\end{aligned}
$$

After some rearrangement and substituting Eq. (6) into Eq. (8):

$$
\begin{aligned}
\ln F_{t}= & \phi \sum_{i=1}^{l} \beta_{j} Y_{j t}+\sum_{i=1}^{m} \alpha_{i} \ln X_{i t}+(1-\phi) \ln F_{t-1} \\
& -(1-\phi) \sum_{i=1}^{m} \alpha_{i} \ln X_{i t-1}-(1-\phi) u_{t-1}+\phi \epsilon_{t}+u_{t}
\end{aligned}
$$

If the consumer adjusts instantaneously $(\phi=1)$, Eq. (9) is reduced to:

$$
\ln F_{t}=\sum_{i=1}^{m} \alpha_{i} \ln X_{i t}+\sum_{j=1}^{l} \beta_{j} \ln Y_{j t}+\nu_{t} \quad \ldots
$$

where $v_{t}=u_{t}+\epsilon_{t}$.

If the stock of appliance holdings and their rate of utilization include the same explanatory variables, namely, income, price of gas, price of electricity, temperature etc., Eq. (10) can be simplified:

$$
\ln F_{t}=\sum_{K=1}^{n} \gamma_{K} \ln Z_{K t}+\nu_{t}
$$

where

$$
\begin{aligned}
& \gamma_{K}=\left(\alpha_{K}+\beta_{K}\right) \\
& Z_{K}=X_{K}=Y_{K}
\end{aligned}
$$

Eq. (11) is estimated separately for per capita consumption of electricity, per capita consumption of gas and per capita joint consumption of gas and electricity as dependent variables, and real per capita income, real price of gas, real price of electricity, and temperature as independent variables. In each regression equation a trend variable, $T$, is also included to capture the influence of changes in tastes and preferences.

The parameter estimates of Eq. (11) are the long-run elasticities. ${ }^{3}$ The short-run elasticities can be derived by eliminating the adjustment lag from the parameters of Eq. (11). To this, we first regress $\ln F_{t}$ on the explanatory variables, $\phi \sum_{K=1}^{n} \gamma_{K} \ln Z_{K t}$ and the lagged value, $(1-\phi) \ln F_{t-1} \cdot{ }^{4}$ This will give the value of the adjustment

${ }^{3}$ See Appendix A.

${ }^{4}$ See Appendix B. 
coefficient, $\phi$. We then multiply the parameter estimates of Eq. (11) with the adjustment coefficient, $\phi$, as:

$$
\eta_{K f}=\phi \gamma_{K} \quad K=1, \ldots, n
$$

where $\eta_{K f}$ is the short-run elasticity of $F$ with respect to variable $Z_{K}(K=1, \ldots, n)$.

Economic theory suggests that if fuel is a normal good, an increase in (real) income will lead to greater utilization of the existing fuel-consuming appliances or addition to the stock of these appliances. Therefore, the expected sign of the coefficient of income would be positive. The sign of coefficients of own prices of natural gas and electricity would be negative. The cross price effect for natural gas and electricity would be positive if they are substitutes and negative if they are complements. The high mean annual temperature in Pakistan suggests that consumption of fuel should increase with the rise in temperature: the coefficient for temperature should be positive.

\section{DATA AND EMPIRICAL RESULTS}

Each demand equation was estimated from the annual data for 1960 to 1981 . The data for total residential consumption of natural gas and electricity are taken from the Energy Data Book, 1979 [14] and Energy Year Book, 1981 [13]. Data on consumption of all fuels are measured in per capita TOE per year. Data on consumption of natural gas and electricity are obtained from the same sources. The price of natural gas is measured in Rupees per Million Cubic Feet and the price of electricity is measured in Rupees per Million KWH. Prices of fuels were first converted into Rupees per TOE and then expressed in real term by deflating them with the Wholesale Consumer Price Index of $1959-60$ as the base year. Data for population, the wholesale consumer price index $(1959-60=100)$ and real gross domestic product at constant factor cost $(1959-60=100)$ are taken from Pakistan Economic Survey, 1980-81 [10]. An average of the difference of the Mean of Maximum and Mean of Minimum temperatures of Karachi, Lahore, Rawalpindi, Peshawar and Quetta is calculated in Celsius. The figures for temperature are taken from the Statistical Yearbook [11].

Four different versions of the final model (Equation 11) have been estimated. In the first version of the model, the regression equations of natural gas and electricity are estimated using five explanatory variables, viz. income, price of natural gas, price of electricity, temperature and the trend variable. In each equation, prices of both natural gas and electricity are included to test the interrelationship between these two types of fuels as competitors or complements.

In the second version of the model, we have regressed consumption of natural gas and electricity on income, temperature and the trend as explanatory variables. The price of natural gas as an explanatory variable enters only in the equation of natural gas, and the price of electricity only in the equation of electricity. If our regression results are not significant with the former specification of the demand function, then we hypothesize that a mere inclusion of own price as explanatory variable would make the parametric estimates more reliable.

In the third case, we have attempted the above two sets of equations together. Consumption of natural gas and electricity is summed up and regressed on five explanatory variables, viz. income, price of gas, price of electricity, temperatures and the trend. The hypothesis tested here is whether the consumption level changed during the period taking each fuel separately and then jointly.

The fourth case is similar to the third, with the difference that a weighted average of prices of natural gas and electricity is substituted for their separate price.

\section{Regression Results}

The OLS technique is applied to estimate per capita consumption of natural gas and electricity. The results are presented in Table 1. The sign of the income elasticity of consumption of natural gas and electricity or both fuels together is positive and statistically significant at the 0.05 level.

The value of the long-run income elasticity is relatively higher than found in studies for developed countries. It seems reasonable because in developing countries as incomes rise additional expenditures are allocated more than proportionately to heat, light, electrical appliances, etc. Therefore, expenditures on fuel would represent a large fraction of the consumer's budget in low-income countries, producing a relatively higher income elasticity estimate [16].

The estimates for income elasticity in this study are also higher than those for other developing countries. This may be explained by several factors. First, our estimate for income elasticity is based on only commercial fuels consumed in the residential sector, while studies for other developing countries have estimated income elasticity from commercial and non-commercial fuels consumed in all sectors of the economy. Since there is considerable substitution within different types of fuels in the aggregate energy consumption, income elasticity would be smaller for it than for consumption of natural gas and electricity in a particular sector of the economy [4].

Secondly, natural gas and electricity are not the basic household fuels in Pakistan. A vast majority of people in the country rely on non-commercial sources of energy for cooking, heating, etc. Commercial fuels are consumed mainly in urban centres and where the real per capita income is higher than the national average [12].

The price elasticities of natural gas and electricity show a somewhat heterogeneous pattern. The own price elasticity of natural gas in the OLS estimate was significant for all equations. It became relatively insignificant when estimated by the GLS method. The own price elasticity of electricity was either positive, though statistically insignificant (see Reg. Eqs. 2 and 7), or negative but low and with poor level of significance (see Reg. Eqs. 3, 5, 6 and 8). 
Regression Results of Demand for Fuel in Pakistan (1959-60 to 1980-81)

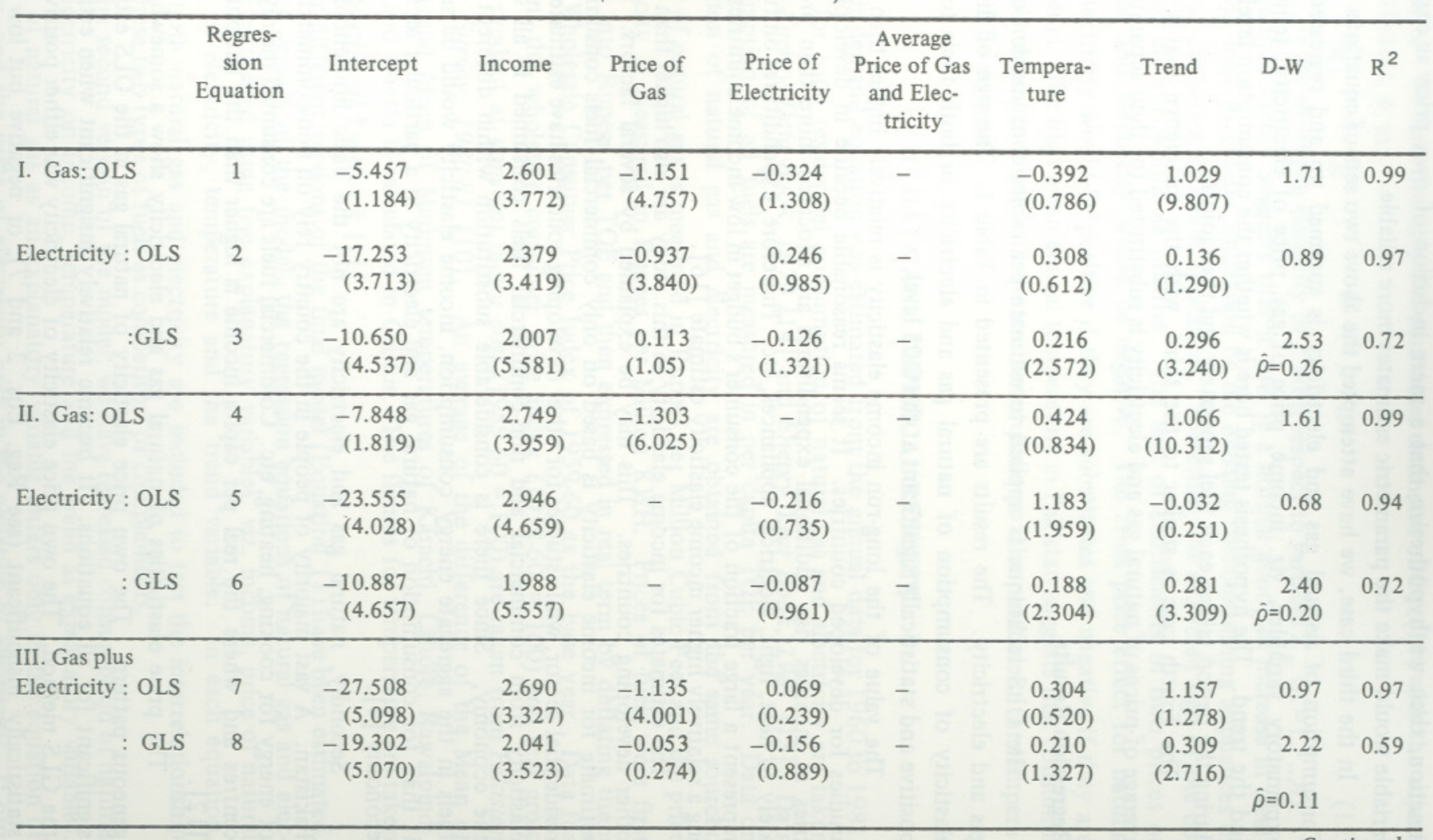

Table 1 - Continued

\begin{tabular}{|c|c|c|c|c|c|c|c|c|c|c|}
\hline $\begin{array}{l}\text { IV. Gas plus } \\
\text { Electricity : OLS }\end{array}$ & 9 & $\begin{array}{r}-18.347 \\
(2.208)\end{array}$ & $\begin{array}{c}2.729 \\
(3.419)\end{array}$ & - & - & $\begin{array}{c}-1.083 \\
(3.267)\end{array}$ & $\begin{array}{c}0.634 \\
(0.980)\end{array}$ & $\begin{array}{c}0.039 \\
(0.303)\end{array}$ & 0.70 & 0.96 \\
\hline : GLS & 10 & $\begin{array}{r}-17.709 \\
(4.285)\end{array}$ & $\begin{array}{c}2.024 \\
(3.597)\end{array}$ & - & - & $\begin{array}{c}-0.216 \\
(1.69)\end{array}$ & $\begin{array}{c}0.201 \\
(1.320)\end{array}$ & $\begin{array}{c}0.306 \\
(2.630)\end{array}$ & $\begin{array}{r}2.21 \\
\hat{\rho}=0.10\end{array}$ & 0.58 \\
\hline
\end{tabular}

Note: Figures in parentheses are t-statistics. 
According to official estimates in Pakistan, the ratio of consumption of natural gas to electricity was $2: 1$ in $1959-60$, increasing to $65: 1$ in 1980-81. In the twentytwo-year period, consumption of natural gas increased 30 times more than the increase in the consumption of electricity. On the other hand, prices of both natural gas and electricity decreased by almost the same proportion in real terms $[13 ; 14]$. Therefore, a very large percentage increase in the consumption of natural gas relative to electricity, with the same percentage decline in prices of each, resulted in a large and statistically significant price elasticity of natural gas. The price elasticity of electricity had either a negative sign or positive and was inconsistent with economic theory. The magnitude of increase in natural gas relative to electricity also suggests that demand for natural gas was supply-constrained, particularly in early years, causing the estimation problem.

The same argument applies to other regression equations representing joint consumption of natural gas and electricity. In Reg. Eq. 7, the price elasticity of natural gas remains negative and statistically significant while the price elasticity of electricity becomes positive but statistically insignificant. The effect of a weighted average percentage change in prices of natural gas and electricity on the joint consumption of natural gas and electricity is negative and statistically significant (see Reg. Eq. 9).

From the price elasticities of natural gas and electricity, we can also conclude that natural gas and electricity in Pakistan are not competitors (see Reg. Eqs. 1 and 8). In fact, each fuel has its own specific use. Natural gas is used for cooking, space heating, water heating, etc. Electricity is used for lights, fans, refrigerators, airconditioners, televisions, stereo components, etc.

In the second set of regressions, multicollinearity (not reported here) has decreased; the level of significance of the own price elasticity of natural gas has increased; and, more importantly, the own price elasticity of electricity has become consistent with theory. This supports our hypothesis that besides income, temperature and the trend variable, the own price of the fuel should be included in the equations of natural gas and electricity.

The income and price elasticities of joint consumption of natural gas and electricity are equivalent, in magnitude and significance, to the elasticities of natural gas and electricity when used separately. This rejects our hypothesis that consumption behaviour differs between joint and separate uses of natural gas and electricity. The mean maximum and minimum temperatures for large cities in Pakistan show that there was little variation in temperature over the period under study. Therefore, the elasticity of temperature was small and statistically insignificant. The positive sign of the elasticity of temperature implies that due to tropical climate of the country, fuel is required to operate fans, air conditioners, refrigerators, generators, suction pumps, etc. ${ }^{5}$

${ }^{5}$ The overall climate of the Indus basin of Pakistan, in which the largest urban centres are located, is hot (arid) and even humid for about 8 to 9 months in the year.
The regression equations estimated by OLS had small Durbin Watson statistics, reflecting a high degree of autocorrelation. This in turn results in smaller variance or overstatement of $\mathrm{t}$-values of parameters. This was corrected by estimating these equations by GLS of autoregressive of order 1 . This considerably improved the DW statistics and made the parametric estimates more reliable. The high values of R-square for all equations demonstrate that they have a 'good' fit. About 99 percent of the variation in the demand for natural gas and electricity could be explained by the independent variables. However, a note of caution is necessary here. The large intercepts with significant t-values represent the fact that the excluded variables could have significant effect on the consumption of natural gas and electricity. Moreover high R-square and low levels of significance of the coefficients require great care in interpreting the results. However, a high R-square and statistically significant values of income, price of natural gas and weighted average price of natural gas and electricity establish the importance of this study.

\section{Income and Price Elasticities}

The long- and short-run income and price elasticities of demand for natural gas and electricity are given in Table 2. The availability of substitutes of a good and possibility of reallocation of resources from one good to another are usually greater in the long than in the short run. Therefore, elasticity of demand of a good would tend to be larger in the long run. The difference in long- and shortrun elasticities can be obtained by the magnitude of adjustment coefficient, $\phi$. The smaller the value of $\phi$, the lower is the possibility of instantaneous adjustment and the larger will be the deviation of long-run elasticity from its short-run magnitude. In this study, the values of $\phi$ are estimated as .29 for electricity, .28 for natural gas and .27 for both natural gas and electricity. This implies a slow rate of adjustment of fuel-consuming appliances in the residential sector of Pakistan.

Table 2

Long-Run and Short-Run Income and Price Elasticities

\begin{tabular}{llccc}
\hline & & Natural Gas & Electricity & $\begin{array}{c}\text { Natural Gas plus } \\
\text { Electricity }\end{array}$ \\
\hline Income: & Long Run & 2.74 & 2.94 & 2.77 \\
& Short Run & 0.77 & 0.85 & 0.73 \\
Price: & & & \\
& Long Run & -1.30 & -0.22 & -1.08 \\
& Short Run & -0.36 & -0.06 & -0.29 \\
\hline
\end{tabular}

Sources: Table 1,

Appendices A and B. 
This is understandable because of insufficient information and limited opportunity of diffusion of new products in low income countries. The low rate of increase of real per capita income in Pakistan during the period under study was another factor that greatly constrained the households to hold on to the existing stock of appliances. To this we should add the argument that the repair facilities for appliances were available at reasonable cost [3] .

\section{POLICY IMPLICATIONS AND CONCLUSION}

The aim of this study was to estimate elasticities of residential demand for fuel in Pakistan and to verify if they were consistent with a priori economic theory. Values of the demand elasticities for all fuels with respect to income and price were statistically significant and consistent with the theory. These results on elasticities of residential demand for fuel have important policy implications. They can help in answering several important questions; e.g. by how much should the price of a particular fuel increases in order to restrain the excess demand for that fuel? What proportion of the additional income would a consumer spend on fuel? Does he consider different types of fuels as substitutes or complements? The answers to these questions would be critical to authorities regulating the market for fuel. For example, our results would allow them to estimate the required adjustment in the direction and magnitude of a shock in the fuel sector.

Several possible suggestions for further research emerge from this study. For one thing, all economic variables could be defined with reference to the household and not to the consumer. Secondly, the different blocked prices of natural gas and electricity could be used for a single (average) price of natural gas and electricity. Finally, the figures for urban and rural per capita income should be substituted for national per capita income. 


\section{Appendix A}

Due to the assumption of instantaneous adjustment $(\phi=1)$, the coefficients of Equation 11 are long-run elasticities of demand. The long-run elasticity of demand for fuel with respect to $Z_{K}$ is:

$$
\frac{d \ln F_{t}}{d \ln Z_{K t}}=\frac{d F_{t}}{F_{t}} / \frac{d Z_{K t}}{Z_{K t}}=\gamma_{K} ; K=1, \ldots, n
$$

The short-run elasticity of demand can be estimated by the following method. Assume that $X_{i t}=X_{i t-1}$. Equation 9 can be written as:

$$
\begin{gathered}
\ln F_{t}=\phi \sum_{j=1}^{l} \beta_{j} \ln Y_{j t}+\phi \sum_{i=1}^{m} \alpha_{i} \ln X_{i t}+(1-\phi) \ln F_{t-1} \\
-(1-\phi) u_{t-1}+\phi \epsilon_{t}+u_{t}
\end{gathered}
$$

Corresponding to Equation 11, Equation A-2 can be written as:

$$
\begin{array}{r}
\ln F_{t}=\phi \sum_{K=1}^{n} \gamma_{K} \ln Z_{K t}+(1-\phi) \ln F_{t-1} \\
-(1-\phi) u_{t-1}+\phi \epsilon_{t}+u_{t}
\end{array}
$$

The short-run elasticity of demand for fuel with respect to $Z_{K}$ (from Equation A-3) will be :

$$
\frac{d \ln F_{t}}{d Z_{K t}}=\frac{d F_{t}}{F_{t}} / \frac{d Z_{K t}}{Z_{K t}}=\phi \gamma_{K} ; K=1, \ldots, n
$$




\section{Appendix B}

The value of $\phi$ can be estimated by the following method: Assume that $\ln X_{i t}=\ln X_{i t-1}$; Eq. (9) can be written:

$$
\begin{aligned}
\ln F_{t}= & \phi \sum_{j=1}^{l} \beta_{j} \ln Y_{j t}+(1-\phi) \sum_{i=1}^{m} \alpha_{i} \ln X_{i t}+\phi \sum_{i=1}^{m} \alpha_{i} \ln X_{i t} \\
& +(1-\phi) \ln F_{t-1}-(1-\phi) \sum_{i=1}^{m} \alpha_{i} \ln X_{i t}+\phi \nu_{t}
\end{aligned}
$$

or

$$
\ln F_{t}=\phi\left(\sum_{j=1}^{l} \beta_{j} \ln Y_{j t}+\sum_{i=1}^{m} \alpha_{i} \ln X_{i t}\right)+(1-\phi) \ln F_{t-1}+\phi v_{t}
$$

Corresponding to Eq. (11), Eq. (B-2) can be written:

$$
\ln F_{t}=\phi \sum_{K=1}^{n} \gamma_{K} \ln Z_{K t}+(1-\phi) \ln F_{t-1}+\phi \nu_{t}
$$

The parametric estimates of Eq. (B-3) will give the value of $\phi$.

\section{REFERENCES}

1. Berndt, E. R. and G. C. Watkins. "Demand for Natural Gas: Residential and Commercial Markets in Ontario and British Columbia". Canadian Journal of Economics. February 1977.

2. Dutta, M. Econometric Methods. Cincinnati, Ohio: South-Western Publishing Co. 1975.

3. Ebinger, C. K. Pakistan: Energy Planning in a Vortex. Bloomington: Indiana University Press. 1981.

4. Hoffman, Lutz. "Energy Demand in Developing Countries: Approaches to estimation and Projection". Workshop on Energy Data of Developing Countries. Vol. 1. Paris: Organisation for Economic Cooperation and Development. 1979.

5. Houthakker, S., P. Verliger, and D. Sheehan. "Dynamic Demand Analyses for Gaasoline and Residential Electricity". American Journal of Agricultural Economics. No. 2. May 1974. pp. 412-418.

6. Iqbal, Mahmood. "Estimates of Gasoline Demand for Automobiles in Pakistan”. Canada: Simon Fraser University. 1983. (Unpublished)

7. Javed, Anees. "Household Demand for Natural Gas in Pakistan". The Pakistan Development Review. Winter 1978.

8. Koutsoyiannis, A. Theory of Econometrics. The Macmillan Press Ltd. 1973.

9. Murray P., R. Spann, L. Pulley and E. Beavris. "The Demand for Electricity in Virginia". The Review of Economics and Statistics. October 1978.

10. Pakistan. Ministry of Finance. Pakistan Economic Survey, 1980-81. Islamabad.

11. Pakistan. Central Statistical Office. 25 Years of Pakistan in Statistics, 1947-72. Karachi.

12. Pakistan. Central Statistical Office. Household Income and Expenditure Survey, 1971-72. Karachi.

13. Pakistan. Directorate General of Energy Resources. Energy Year Book 1981. Islamabad.

14. Pakistan. Energy Resources Cell. Energy Data Book, 1979. Islamabad.

15. Parikh, J. K. Energy Systems and Development: Constraints, Demand and Supply of Energy for Developing Regions. Delhi: Oxford University Press. 1980.

16. Pindyck, R. S. The Structure of World Energy Demand. Cambridge, Mass.: The MIT Press. 1979.

17. Riaz, T. "A Long-Range Energy Sector Plan for Pakistan". Pakistan Development Review. Autumn 1981. 
18. Taylor, Lester. "The Demand for Electricity: A Survey". The Bell Journal of Economics. Spring 1975.

19. World Bank. Pakistan: Issues and Options in the Energy Sector. Report No. 2953-Pak. Washington, D.C. 1980. 